\title{
Innovative Benthic Lander for Macroalgae Monitoring in Shallow-Water Environments
}

\author{
João Pedro Santana ${ }^{1} \cdot$ Nuno Mathias ${ }^{1} \cdot$ Richelle Hoveling $^{2} \cdot$ Hugo Alves $^{1} \cdot$ Tiago Morais $^{1}$
}

Received: 3 June 2019 / Accepted: 29 August 2019 / Published online: 18 June 2020

(C) The Author(s) 2020

\begin{abstract}
The colonization of underwater environments by exotic seaweeds is causing major ecological problems around the world. This project, referred to AMALIA, aims to transform this current ocean threat into an opportunity by adding value to the macroalgae present off the northwest of the Iberian Peninsula. To do so and to observe the presence of seaweeds in situ, an ocean modular submersible platform was developed. This platform was designed to be capable of detecting and surveying surges of invasive seaweeds while withstanding sea conditions. Conceptual designs followed by a screening process were performed, taking into consideration criteria such as operational range and modularity. An open-frame lander was considered and further developed using buckling criteria. In parallel, a state-of-the-art monitoring system was created using spectral imaging, allowing for the future creation of a macroalgae identification system. In addition, sensorial systems for characterizing growth conditions were introduced. Laboratory trials were executed to assess the capability of the system, and sea trials are currently being performed. Numerical simulations and laboratory trials indicate that the structure is fully capable of being deployed for shallow-water environments with a state-of-the-art invasive seaweed monitoring system while maintaining a high degree of modularity.
\end{abstract}

Keywords Benthic landers $\cdot$ Ocean surveillance $\cdot$ Environmental protection $\cdot$ Ocean technology $\cdot$ Marine instrumentation

\section{Introduction}

The ocean has a fundamental role in the correct balance of ecosystems, in climate pattern, and in air quality, thus affecting the surrounding coastal and land wildlife (US Department of Commerce 2018). However, despite its value, a considerable portion of the ocean remains unexplored, as expressed by the Ocean Portal Team: "Deep below the ocean's surface is a

\section{Article Highlights}

- Conceptual design of open-frame landers

- Structural dimensioning for deep-sea applications

- Development of a state-of-the-art hyperspectral camera for monitoring seaweeds

- Laboratory and long-term sea trials for validation

Nuno Mathias nmathias@inegi.up.pt

1 INEGI-Institute of Science and Innovation in Mechanical and Industrial Engineering, Rua Dr. Roberto Frias 400 Campus FEUP, 4200-465 Porto, Portugal

2 Quest Innovations BV, Industrieweg 41, 1775 PW Middenmeer, The Netherlands mysterious world that takes up 95\% of Earth's living space." (The Ocean Portal Team 2016).

The ocean is home to a large diversity of flora and fauna that are critically adapted to reduced temperatures, high pressure, and low light exposure, resulting in unique features with the potential to be researched and extracted for industrial use. Such potential can range from new resources with unknown potential to new information on marine fauna and flora. With this information, a concrete stock evaluation can be performed, allowing for improved application of biodiversity protection measures. In fact, with regard to coastal areas, the loss of oyster and coral reefs has persisted over several decades, creating a need for a thorough monitoring process. Moreover, the appearance of harmful algal blooms, offshore pollution, and oxygen depletion have increased, decreasing water quality and damaging ecosystems worldwide (Barbier 2017).

In this aspect, benthic macroalgae have been the subject of increased focus in the research sector given their constitution and industrial potential, which can add significant value to the food, feeding, pharmaceutical, and cosmetic industries. The main advantages when using macroalgae as a biological resource are their fast growth, the ability to grow in all climate zones, and their high content of valuable carbohydrates, 
proteins, and lipids (State of Green 2018). In addition, an analysis of their importance to marine ecosystems indicates that macroalgae play an essential part by providing habitat and nutrients in the benthic food chain (Van der Wal et al. 2014). Therefore, rigorous control of macroalgae may have a direct effect on the upper food chain levels.

The main objective of this project is to design and construct a submersible modular system for seafloor monitoring, capable of conducting in situ analysis of invasive macroalgae in shallow-water environments, with the specific focus area being the northwest coast of the Iberian Peninsula. This prototype is the first with an expandable design, thus providing room for the implementation of an autonomous spectral imaging system for the acquisition of information on macroalgae growth at the benthic zone. The gathered information will be used for the further development of a macroalgae identification system. The goal of this paper is to present design considerations regarding the conceptual phase, the considered material, the structural dimensioning, the systems incorporated in this first prototype, and the laboratory trials performed for this prototype.

Regarding methodology and procedures, the existing landers and the respective technologies applied for ocean applications were evaluated in the first stage. In the second stage, the project was divided into two sub-projects concerning (1) the lander structure and (2) hyperspectral camera, sensorial system, and energy requirements. For the lander, several concepts were designed and later submitted to a selection process by employing a given set of criteria. After the concept was selected, two load cases were considered: (1) when the structure is subjected to hydrostatic pressure and (2) when the structure is being lowered. In parallel, a macroalgae monitoring system was developed. Finally, laboratory trials were performed to validate the system. Sea trials are currently ongoing.

\section{State-of-the-art}

Seafloor exploration has been limited because of high pressures and low temperatures, creating the need for further development of marine technologies for ocean exploration. Manned and tethered submersibles have been used with a considerable rate of success but at a considerable risk, nonetheless. Given the safety concerns of the latter, a vehicle that can perform underwater activities without any physical connection to the surface needs to be developed. The emergence of a completely autonomous vehicle or structure would ease seabed exploration. However, when an unattached system is used, new engineering challenges arise, such as communication barriers between the surface and the vehicle, due to increased difficulty in spreading electromagnetic waves (Tengberg et al. 1995). To this end, autonomous underwater vehicles (AUVs) and benthic landers are an alternative to remotely operated vehicles and manned submersibles.

AUVs are particularly suited for small, short-range operations, such as retrieving seafloor image frames of a specific location for a short period (usually in the range of a few hours). However, over a long time or when a time-lapse comparison of static images is required, benthic landers present a clear advantage. Given their static nature, landers enable easy capture of the same picture frame over a considerable amount of time, allowing for a more complete monitoring of macroalgae growth, for example. A comparison shows that an AUV can capture the same picture frame by using a considerable amount of power, and a minor disturbance could reduce the quality of the image frame (Geyer 2011; Wynn et al. 2014).

\subsection{Benthic Landers}

In general, benthic landers, also known simply as landers, are any unmanned, unattached, autonomous, and instrumented underwater vehicle capable of gathering physical and chemical variables in situ over a given period. Their operational time can range from a few days, usually for biological studies, to several years, for physical oceanography studies (Ferreira et al. 2014; Tengberg et al. 1995). Deployment is usually performed in either one of two modes: (1) a free-fall mode, where control over the precise landing position is limited; or (2) a highprecision mode, commonly used to measure geomorphological features. Concerning retrieval, two solutions are available: (1) the lander has ballast weights attached to it, which are then released; and (2) the lander has a variable buoyancy system that allows it to resurface. An analysis of the loads applied on these structures reveals two main categories: static loads, such as the hydrostatic pressure (Eq. (1)), and dynamic loads, such as the loads produced by waves and currents.

$p_{\text {total }}=p_{\text {atm }}+\rho \cdot g \cdot h$

where $p_{\text {total }}$ is the total pressure, $p_{\text {atm }}$ is the atmospheric pressure (considered $0.1 \mathrm{MPa}$ ), $\rho$ corresponds to the water density (considered $1027 \mathrm{~kg} / \mathrm{m}^{3}$ ), $g$ represents the standard Earth acceleration, and $h$ is the distance to the free surface.

Weight presents a major problem for a controlled descent, because descent speeds and currents might prevent a successful landing. To prevent these problems, the structure must (1) not comprise a large projected area in the vertical (diving) direction, allowing for a reduction of hydrodynamic effects, such as drag and added mass; and (2) minimize the impact of an uncontrolled landing, by, for instance, producing landers with negative buoyancy or using suspended ballast weight beneath the lander. Moreover, most constructors design easily dismountable outer frames to ease transport (Tengberg et al. 1995). 
Landers are frequently classified based either on their range of operation or their application and measuring equipment. As such, concerning their range of operation, the following categories are generally applied: shallow-water, mid-water, or deep-water landers. Shallow-water landers usually operate at a maximum depth of $500 \mathrm{~m}$ (Shah 2007) in a near-offshore zone. Here, the main loads applied on the structure have a dynamic nature (the static loads are virtually negligible), making it important to minimize the projected area of all equipment reduce the effect of drag. Mid-water landers refer to landers working in the range of up to $2500 \mathrm{~m}$ (Shah 2007), where static loads exceed dynamic loads both in intensity and impact. At depths of more than $2500 \mathrm{~m}$, deep-water landers must be used. As a consequence of this increase in depth, static loads increase proportionately and dynamic loads tend to be negligible. In addition, a variable buoyancy system must be installed due to the impracticability of manned recovery (Tengberg et al. 1995).

When landers are classified according to their application and measuring equipment, three categories are usually considered: micro open-frame, macro open-frame, and flat shape landers. Micro open-frame landers are modular structures capable of carrying various instruments for monitoring and measuring in situ. These landers have an open-framed structure to minimize the effects of drag, allowing water to flow through the instrument and sensor payload. Some examples are the HADAL lander and the Medusa Lander (HADES 2014). Macro open-frame landers are similar to the previous ones, with the difference lying in their operational range. Macro open-frame landers are used for longer-term deployments when compared with their micro counterparts. Some examples of these landers are the K/MT 100 lander from KUM Kiel and the DOBO lander from Aberdeen Ocean Lab (K.U.M. Umwelt- und Meerestechnik Kiel GmbH 2002; Silva et al. 2016). Flat-shaped landers use a flat-shaped structure to remain on the seafloor, where low dynamic effects are verified. These landers are mainly used for deep-sea applications. Some examples of these types of landers are K-Lander from KONGSBERG Modular Subsea Monitoring Network, the OBSEA Lander from the Polytechnical University of Catalunya, and, more recently, the AMERIGO Lander (Kongsberg Group 2015; Spagnoli et al. 2019; Universitat Politécnica de Catalunya 2019).

Concerning materials, to make the system as cost efficient as possible, a correct balance must be achieved between structural stability-namely, resistance to traction, flexion, and compression - and minimal material cost. Given that static forces are linear, the focus must rely on dynamic forces. Moreover, the use of non-corroding materials is key for marine applications.

The most frequently used material for these systems is aluminum as an alternative to stainless steel due to its light weight and greater corrosion resistance. Titanium is also commonly used. However, its high price and difficult welding and polishing make it unappealing for most cases (Tengberg et al. 1995). Galvanized steel, despite being more cost-efficient, presents several disadvantages, such as difficult galvanization in closed sections, e.g., cylindrical tubes. Composite structures are not in use due to their low mechanical resistance (Tengberg et al. 1995). A metal composite combination where the latter (composite) encloses the first (metal) is currently used to minimize corrosion (European Sea Observatory Network 2008). Polyoxymethylene (POM) is a highperformance thermoplastic whose characteristics, such as reduced price and low density, make it a better alternative to work with than aluminum (Kramer and Demer 1961; Monnerie 1990) (Table 1).

\subsection{Spectral Imaging Systems}

Hyper- and multispectral data are typically collected (and represented) as a three-dimensional dataset: a data cube, with spatial information collected in the $x y$-plane (front plane) and spectral information represented in the $z$-plane. The objective of spectral imaging is to obtain spectral information for each pixel in the image. This spectral information can be used to identify objects on the basis of their spectral features. The quality and quantity of the spectral content in the data cube are defined by the spectral resolution and the amount of spectral bands that are recorded by the spectral system. In multispectral systems, the spectral data comprise several $(<20)$ discrete spectral bands, and a hyperspectral system records the spectral data over a continuous spectral range using narrow spectral bands (Figure 1) (Lu et al. 2019; Qin et al. 2013). The scene of interest is shown in conventional RGB (Figure 1(a)), and the information obtained from hyperspectral (HSI) and multispectral imaging (MSI) is shown as a reflectance spectrum (Figure 1(b)). The data cubes represent the spatial and spectral information for HSI (Figure 1(c)) and MSI (Figure 1(d)). For every pixel in the image, the spectral data can be represented as a reflectance spectrum.

The acquisition method for these data cubes using multiand hyperspectral imaging devices can be divided into different scanning groups: spatial scanning, spectral scanning, nonscanning, and spatiospectral scanning (Figure 2). The data cubes can be acquired by using different types of scanning; spatial (line) scanning (Figure 2(a)), spectral scanning (Figure 2(b)), and non-scanning (Figure 2(c)). The colored areas represent the data acquired in one scanning step. The red arrows show the dimension that is scanned in sequential measurement steps.

In spatial scanning systems, the spectral information of a single point or line in the spatial plane $(x, \lambda)$ is projected on the sensor of the system. For the point scanning system, such as a whisk broom scanner, the light of a single point in the image is dispersed into different wavelengths by using a prism or a 
Table 1 Properties of common materials in lander design

\begin{tabular}{llccl}
\hline Material & Density $\left(\mathrm{kg} / \mathrm{m}^{3}\right)$ & $E(\mathrm{GPa})$ & Tensile at yield $(\mathrm{MPa})$ & Corrosion resistance \\
\hline Stainless steel & 7800 & 198 & 350 & Fair \\
Aluminum & 2699 & 68 & 36 & Fair \\
Titanium & 4500 & 831 & 140 & Very good \\
POM & 1400 & 2.95 & 43 & Very good \\
\hline
\end{tabular}

grating. To complete the data cube, scanning has to be performed in both spatial directions. In case of a line scanning system, such as a push broom scanner, a line or strip of the image is directed into a slit and dispersed through a prism or a grating onto the sensor of the system. In this configuration, scanning in one spatial direction is required to complete the data cube (Lu et al. 2019; Qin et al. 2013). Line scanning systems are often applied in remote sensing where mobile platforms, helicopters, drones, and satellites are used to scan an area of interest. This type of scanning requires stabilized mounts or accurate pointing and positioning information for correct reconstruction of the image. More controlled conveyor belt constructions are ideal for line scanning; in this case, the object of interest is moved instead of the camera system. The advantage of this type of system is that a high spectral resolution will provide a large amount of information on the spectral properties of the scanned objects. However, the scan configuration and scan speed pose difficulty in imaging targets that are moving with an uncontrolled behavior during measurement. The spatial resolution will depend on the scan speed and the size of the scene. The data cubes of this type of scanning setup can be large, thus requiring large computational amounts for further data processing.

In a spectral scanning system, monochromatic information of the spatial plane $(x, y)$ is projected on the sensor. By scanning through a sequence of spectral bands, one can record the spectral information of the scene by using optical bandpass filters (fixed or tunable) (Lu et al. 2019; Qin et al. 2013). Given that this stare-down principle has similarities to conventional photographic imaging, it is often perceived as user-friendly. The major disadvantage of this scanning system is spectral smearing that can occur when objects in the scene are moving. An advantage of this type of system is that information can be gathered with high spatial resolution. However, the spectral resolution of the system will dictate the scanning time, thereby
Figure 1 Hyper- and multispectral data acquisition

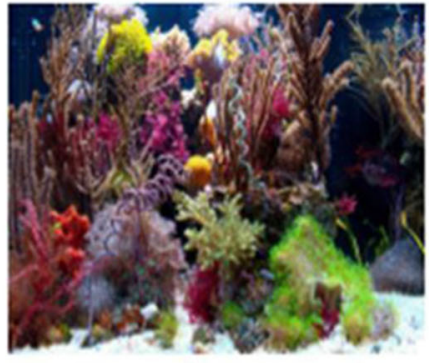

(a) Conventional RGB

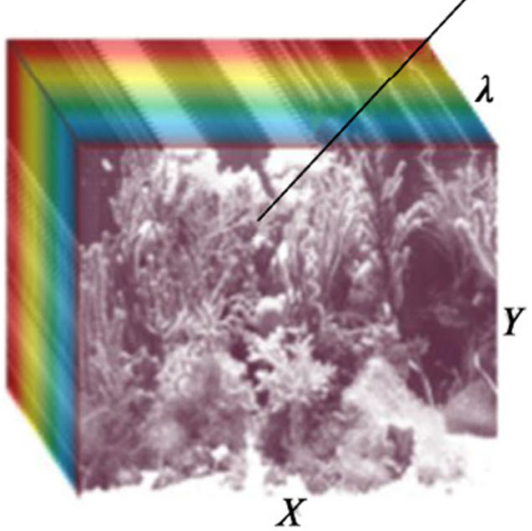

(c) HSI data cube

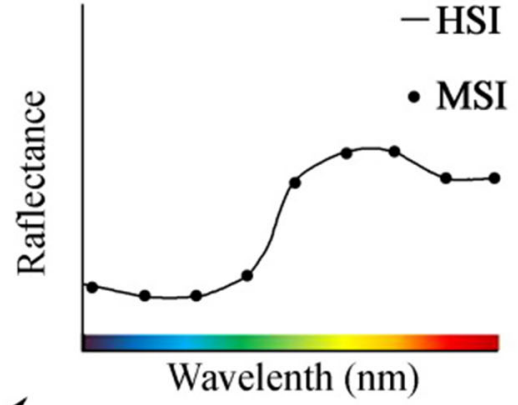

(b) Reflectance spectrum

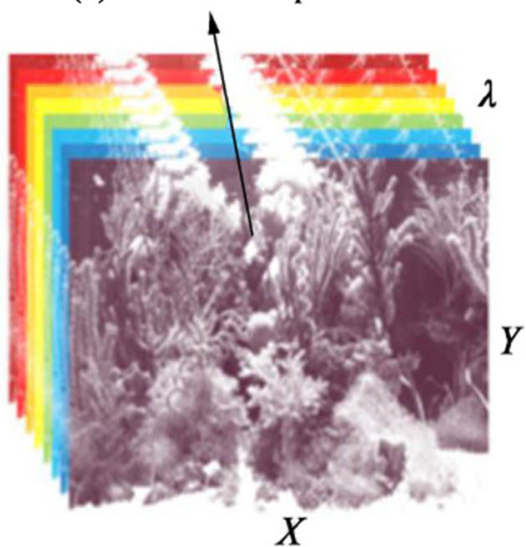

(d) MSI data cube 


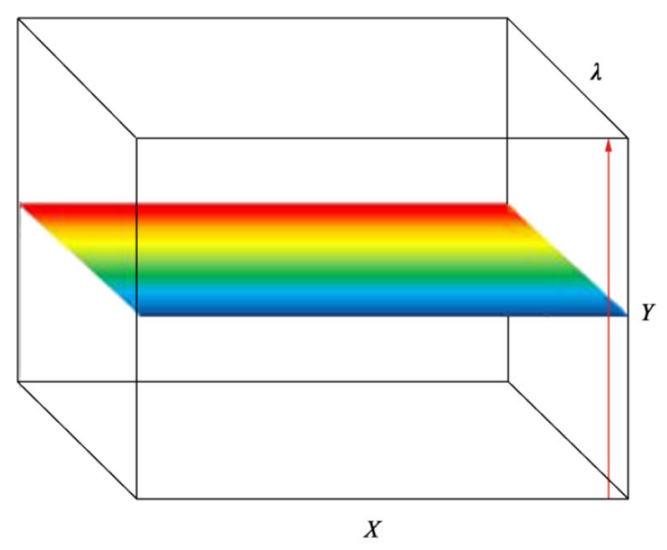

(a) Spatial scanning

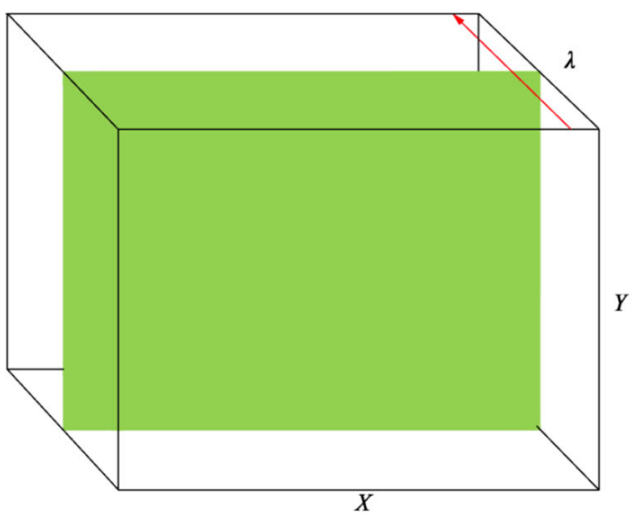

(b) Spectral scanning

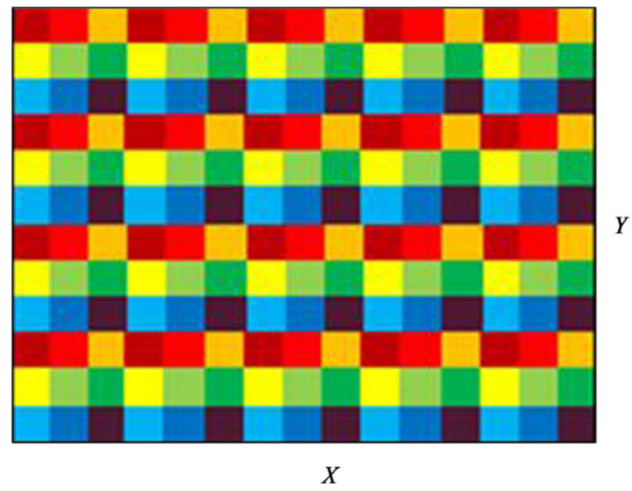

(c) Non-scanning

Figure 2 Scanning modes

causing a limitation in cases where the object is moving and image alignment is difficult. When knowledge about the spectra of the target object is available, choices can be made to optimize the scan speed by decreasing the number of spectral bands that are scanned. The data cubes of this type of scanning setup depend on the number of spectral bands that are scanned and the spatial resolution of the system.

In a non-scanning system, the information of data cube dimensions $(x, y, \lambda)$ is projected on the sensor simultaneously.
This snapshot spectral imaging is obtained though singlepixel-level spectral filtering. The spectral filters of the system are deposited and patterned directly onto the sensor pixels. The data cube can be reconstructed based on the configuration of the filters on the sensor. The advantage of this system is that spectral information can be collected in a single shot, with reasonably low integration times, thereby decreasing the effects of spectral smearing caused by the movement of the sample during the measurement (Lu et al. 2019). A disadvantage of this system is the loss in resolution caused by the size of the mosaic pattern. However, this issue can be overcome with increasing resolution of the sensor when spectral information is constant over a larger area in the image.

An advantage of this type of system is that both spectral and spatial information are recorded during snapshot measurement, thus reducing smearing in cases where the target object is moving in an uncontrolled fashion. A trade-off in this system, as already mentioned, is the decrease in spatial resolution. This decrease will depend on the number of spectral bands placed in the mosaic and the sensor resolution; the latter parameter also dictates the size of the data cube.

\section{AMALIA Lander}

Given that macroalgae thrive mainly in the photic zone $(<200 \mathrm{~m})$, the lander was designed for shallow-water applications and uses an open-frame shape. As such, the lander must be capable of withstanding hydrostatic pressures of up to $2 \mathrm{MPa}$ at $200 \mathrm{~m}$. In addition, the lander was required to have a diminished projected area to reduce the drag effect, and it should have the capacity to observe an area up to $50 \mathrm{~m}^{2}$. To ease transport, the structure was produced in a modular way, allowing for simpler replacement of broken and specialized parts. When underwater cameras are used, a transparent interface between the equipment and the outside environment is required, creating an extra optical component. If not implemented properly, then this interface may disturb the acquired image, causing errors during data acquisition. Two types of interfaces can be applied: flat or dome ports. When adopting flat ports, the most relevant optical phenomena are chromatic aberration, radial and tangential distortion, and refraction (Figure 3(a)-(c)). Dome ports eliminate chromatic aberration, radial and tangential distortion, and refraction effects on the image when aligned with other optical equipment. The major disadvantage with this port geometry, however, is the virtual image effect, which occurs for dome ports used in underwater applications where the lens is divergent, making the focal length negative, i.e., the image is virtual, creating the illusion that the object is closer to the lens than in reality. The decision was taken to house the equipment by using a specialized commercial product, namely, Nautilus 17" glass sphere (Nautilus Marine Services 2019). 


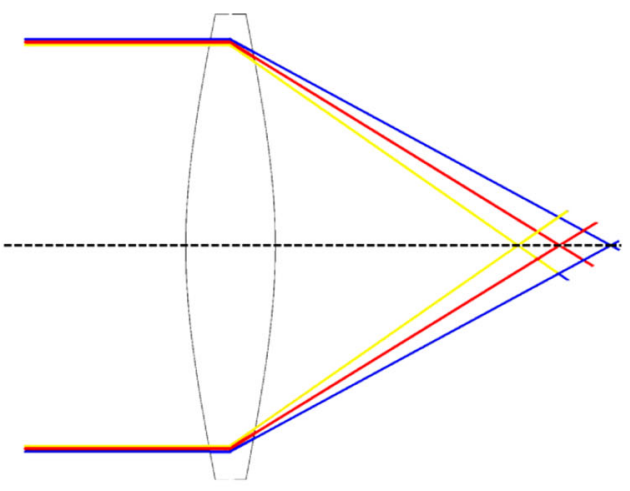

(a) Chromatic aberration

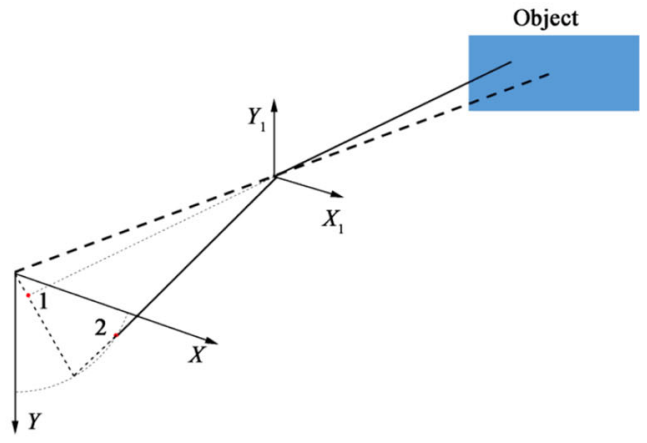

(b) Radial and tangential distortion

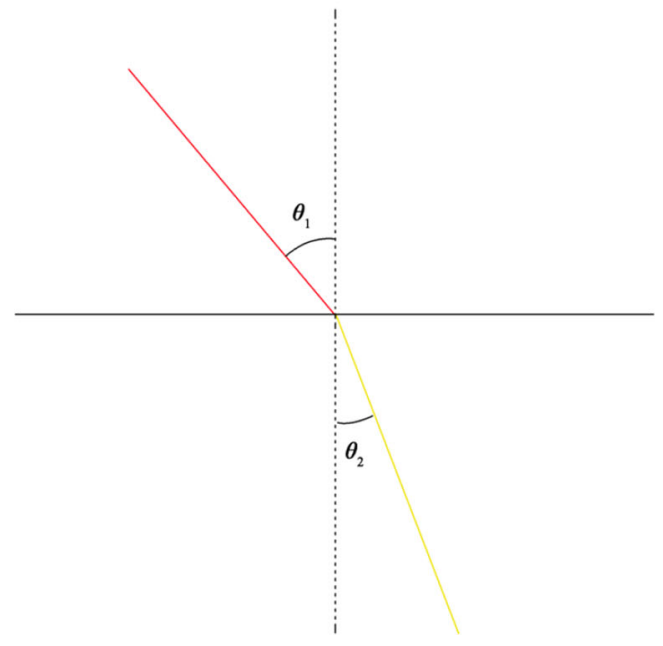

(c) Refraction

Figure 3 Optical phenomena for flat ports

\subsection{Concepts}

Each of the proposed concepts attempts to create a versatile lander that can operate under different circumstances in the photic zone while satisfying the following selection criteria: structural stability, reduced cost, mobility, safety, modularity, monitoring system complexity, environmental impact, and innovation.
The first concept (Figure 4(a)) is a pyramidal open-framed lander with three supports and can be manufactured using any material due to its simple geometry, allowing for a significant cost reduction. The main disadvantage of this design is the low protection offered to the monitoring equipment. Concept 2 (Figure 4(b)) was based on the flat-shaped landers with a rigid central body structure, which relies on its robustness to remain on the seafloor. The same geometrical feature was applied in concepts 3 (Figure 4(c)) and 4 (Figure 4(d)). Concepts 2 to 4 offer greater protection to the monitoring equipment than concept 1 can while maintaining a relatively simple structure. Concept 2 differs from concepts 3 and 4 on the support type, which varies from fixed (for concept 2) to articulated (for concepts 3 and 4 ). One of the main differences between concepts 3 and 4 is the overall shape. A cylindrical shape was applied in concept 3 , while a hexagonal shape was applied in concept 4 . Thus, concept 4 has a greater advantage over concept 3 due to its lower projected area. Moreover, the beams in concept 3 are curved and those in concept 4 are straight, making concept 4 more cost-effective.

Regarding concepts 5 (Figure 4(e)) and 6 (Figure 4(f)), several current practices used in shallow-water landers and their purposes were taken into account for these designs. This type of design has the advantage of offering a greater storage space for instrumentation needed for the spectral imaging equipment. Concept 5 is rigid, making it difficult to transport, and concept 6 has greater modularity, including the ability to be folded for transportation. Nonetheless, the structural stability is considerably more difficult in concept 6 .

On the basis of the selection criteria mentioned earlier, a decision matrix was created to decide which concept to develop further (Tables 2 and 3). Each of these criteria contributes to several parts of the project, e.g., cost has a considerable impact on geometry, fabrication cost, and deployment, whereas monitoring system complexity is mostly related to the complexity of implementing the diverse control systems. Each of the chosen criteria has a variable importance for the final decision and, as such, a specific weight was applied in a scale of 1 (least important) to 5 (most important). The same scale was applied to each of the proposed concepts, with the difference relying on 1 corresponding to not satisfying and 5 to greatly satisfying, instead of the latter.

An analysis of the different concepts clearly indicates that concept 4 (Figure 4(d)) is the one that best suits the project needs. As such, an open-hexagon module was considered with three tubular beams working as supports (one is an articulated one) creating a tripod (Figure 5(a)-(c)). A central module was designed, where the glass sphere is housed, allowing a full $360^{\circ}$ rotation. Finally, given that the area beneath the lander is not suitable for macroalgae growth because of the shade created by the lander, the camera is also capable of rotating in the longitudinal direction, allowing for a more precise evaluation of the area. 
Figure 4 Concepts for the AMALIA lander

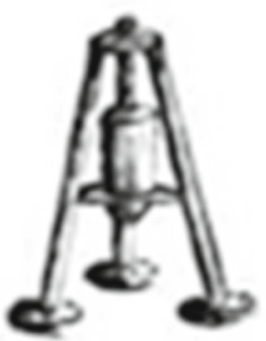

(a) Concept 1

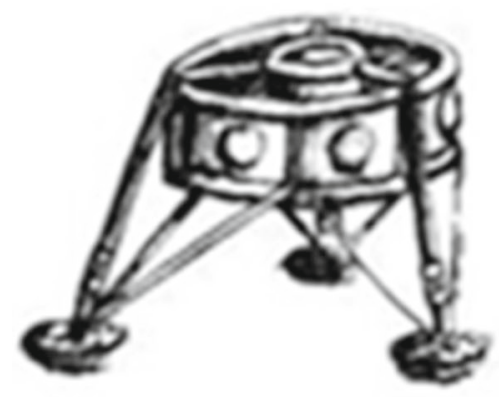

(c) Concept 3

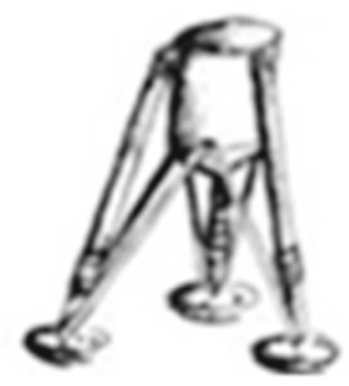

(e) Concept 5

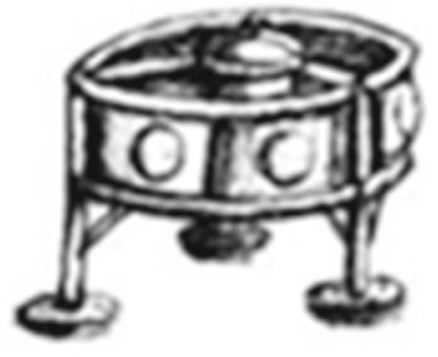

(b) Concept 2

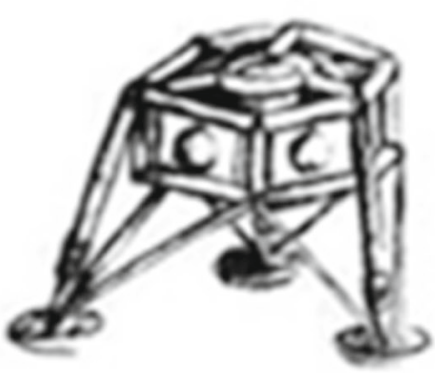

(d) Concept 4

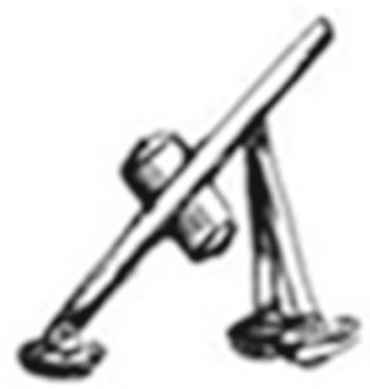

(f) Concept 6
Table 2 Global weight matrix for concepts 1 to 3

\begin{tabular}{|c|c|c|c|c|c|}
\hline Selection criteria & Related to & Weight & $\mathrm{C} 1$ & $\mathrm{C} 2$ & $\mathrm{C} 3$ \\
\hline Cost & $\begin{array}{l}\text { Geometry } \\
\text { Materials and fabrication } \\
\text { Deployment }\end{array}$ & 4 & 4 & 3 & 3 \\
\hline Mobility & $\begin{array}{l}\text { Volume } \\
\text { Weight } \\
\text { Final cost }\end{array}$ & 4 & 4 & 2 & 4 \\
\hline Stability & $\begin{array}{l}\text { Weight } \\
\text { Geometry }\end{array}$ & 3 & 2 & 2 & 4 \\
\hline Safety & Watertightness geometry & 5 & 2 & 3 & 4 \\
\hline Modularity & Geometry & 5 & 1 & 3 & 4 \\
\hline Monitoring system complexity & Complexity of control systems & 2 & 4 & 4 & 4 \\
\hline Environmental impact & Material & 4 & 3 & 2 & 3 \\
\hline Innovation & $\begin{array}{l}\text { Increased value } \\
\text { Market sales }\end{array}$ & 4 & 1 & 1 & 4 \\
\hline Final score & & & 2.5 & 2.4 & 3.6 \\
\hline
\end{tabular}


Table 3 Global weight matrix for concepts 4 to 6

\begin{tabular}{|c|c|c|c|c|c|}
\hline Selection criteria & Related to & Weight & $\mathrm{C} 4$ & $\mathrm{C} 5$ & C6 \\
\hline Cost & $\begin{array}{l}\text { Geometry } \\
\text { Materials and } \\
\text { fabrication } \\
\text { Deployment }\end{array}$ & 4 & 3 & 3 & 4 \\
\hline Mobility & $\begin{array}{l}\text { Volume } \\
\text { Weight } \\
\text { Final cost }\end{array}$ & 4 & 4 & 3 & 4 \\
\hline Stability & $\begin{array}{l}\text { Weight } \\
\text { Geometry }\end{array}$ & 3 & 4 & 4 & 3 \\
\hline Safety & $\begin{array}{l}\text { Watertightness } \\
\text { geometry }\end{array}$ & 5 & 4 & 4 & 3 \\
\hline Modularity & Geometry & 5 & 4 & 4 & 4 \\
\hline $\begin{array}{l}\text { Monitoring system } \\
\text { complexity }\end{array}$ & $\begin{array}{l}\text { Complexity of control } \\
\text { systems }\end{array}$ & 2 & 4 & 4 & 4 \\
\hline Environmental impact & Material & 4 & 3 & 3 & 3 \\
\hline Innovation & $\begin{array}{l}\text { Increased value } \\
\text { Market sales }\end{array}$ & 4 & 4 & 4 & 4 \\
\hline Final score & & & 3.8 & 3.6 & 3 \\
\hline
\end{tabular}

\subsection{Frame Dimensioning and Material Choice}

As mentioned earlier, one of the main goals in lander design is to use a light material, making the lander not only easy to transport but also mechanically sturdy, thus ensuring the protection of the observation system and operability at the required depth. For the lander components (main supports or "articulated legs," secondary supports or "simple legs," and hexagonal hoops), two materials were taken into consideration: steel, due to its high mechanical performance, and POM, due to it being a lightweight alternative. Main and secondary supports are subjected to alternate compression and traction loads due to vertical movement, creating the risk of buckling. In addition, to achieve an observation area of $50 \mathrm{~m}^{2}$, the main support must have a length of $1800 \mathrm{~mm}$. As a first step, various diameters of commercially available beams made of both steel and POM were taken into account (Table 4). To keep the model cost-efficient, the material and diameter chosen for the main and secondary supports were kept equal.

Given that the structure is axisymmetric around the vertical axis, the load on each element is one-third of the total weight. With the use of directional force vectors and force equilibrium, the loads that affect each support were quantified. Considering one main support in compression, buckling can be predicted by using Euler's critical load equation (Domokos et al. 2000; Barbero and Tomblin 1993):

$P_{\text {cr }}=\frac{\pi^{2} E I}{(K L)^{2}}$

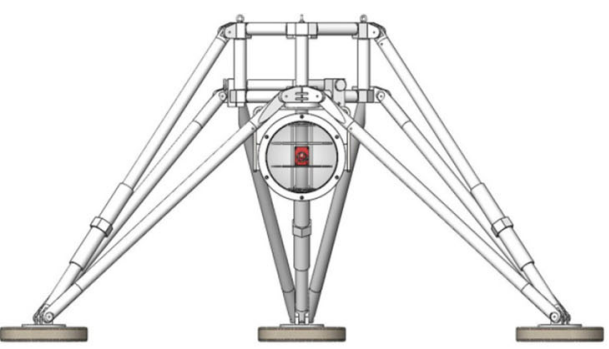

(a) AMALIA lander side view

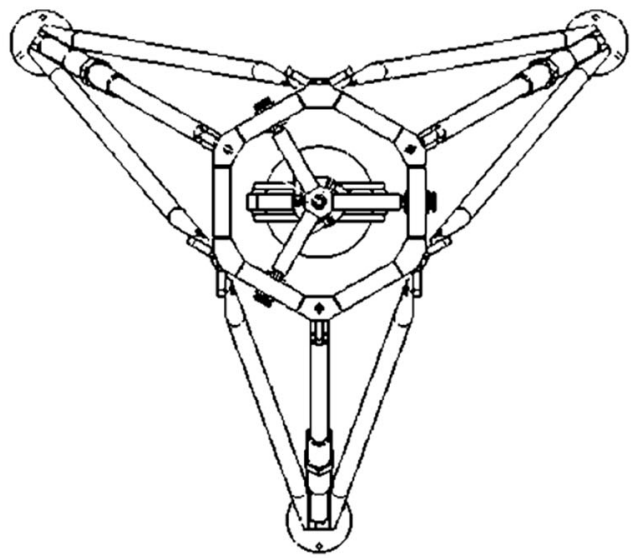

(b) AMALIA lander top view

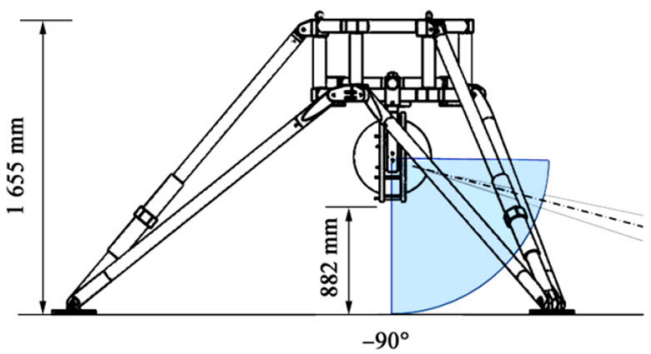

(c) AMALIA lander front view

Figure 5 AMALIA lander

where $P_{\text {cr }}$ is the critical load before buckling, $E$ is the Young's modulus of steel and POM, $I$ is the area moment of inertia for tubes, $L$ is the length of the tube, and $K$ is the column's effective length factor. Given that the beam has bolted joints on both ends, $K$ is assumed to be of unitary value because both ends are pinned (Pierre Beer and Russell Johnston 1981).

Table 4 Profile diameters and lengths used in lander design

\begin{tabular}{lll}
\hline Profile No. & Diameters $(\mathrm{mm})$ & Length $(\mathrm{mm})$ \\
\hline 1 & 70 & 1800 \\
2 & 60 & 1800 \\
3 & 50 & 1800 \\
4 & 40 & 1800 \\
\hline
\end{tabular}


Concerning the safety factor, the following criteria were considered: $S_{\min } \geq 2$ for calculations preventing fracture, $S_{\min } \geq 3$ for calculations preventing bending and buckling, and $S_{\min } \geq 1.2$ for calculations preventing fracture stresses due to cracking (Erhard 2013). Both materials have superior resistance to buckling when the applied load is considered (Table 5). Given that POM is less expensive than steel and no major economic benefit is offered in considering profiles of $60 \mathrm{~mm}$ when compared with profiles of $70 \mathrm{~mm}$, further calculation will account for POM profiles with a $70 \mathrm{~mm}$ diameter.

Given that no buckling effect occurs on the beam, the stress is purely linear. Therefore, stress can be calculated by the following expression:

$\sigma=\frac{F}{A}$

where $\sigma$ is the plain stress, $F$ is the load being applied, and $A$ is the cross-sectional area where the load is applied. The von Mises yield criterion states that, for uniaxial loads $\sigma_{\vartheta}=\sigma$ and given that the load is uniaxial, the stress can be related directly to the yield strength. As a result, the obtained linear stress was below $\sigma_{\text {yield }}=43 \mathrm{MPa}$ (Table 1 ), thus resulting in no risk of plastic behavior. Secondary supports are in pure traction caused by a lower-intensity force in an equal crosssectional area. Thus, we confirm that no plastic deformation occurred either.

\subsection{Load Cases}

A numerical model was created using $70-\mathrm{mm}$ POM profiles (Table 5) for two distinct load cases: (1) continuum operation, where the structure was subjected to thrust, weight, and $2 \mathrm{MPa}$ uniform pressure applied to all surfaces (Figure 6(a)); (2) deployment operation, when the lander interacted with a crane through three eyebolts dispersed symmetrically on the superior hoop (Figure 6(b)). Load case No. 2 also attempts to attest the behavior of the hexagonal hoops and their respective connections. ANSYS Mechanical was used to simulate the stress, strain, and displacements in each one of these cases. The loads in case No. 1 were applied by steps, where the hydrostatic

Table 5 POM and steel critical load and safety factor

\begin{tabular}{|c|c|c|c|c|c|c|}
\hline \multirow[t]{2}{*}{ Profile No. } & \multicolumn{2}{|c|}{ Weight $(\mathrm{kg})$} & \multicolumn{2}{|l|}{$P_{\mathrm{cr}}(\mathrm{N})$} & \multicolumn{2}{|c|}{ Safety factor } \\
\hline & POM & Steel & POM & Steel & POM & Steel \\
\hline $1(70 \mathrm{~mm})$ & 212 & 1170 & 15091 & 710857 & 6.59 & 80 \\
\hline $2(60 \mathrm{~mm})$ & 190 & 1039 & 5717 & 383703 & 3.96 & 48 \\
\hline $3(50 \mathrm{~mm})$ & 172 & 928 & 2757 & 185042 & 2.11 & 61 \\
\hline $4(40 \mathrm{~mm})$ & 157 & 837 & 1129 & 75793 & 0.95 & 12 \\
\hline
\end{tabular}

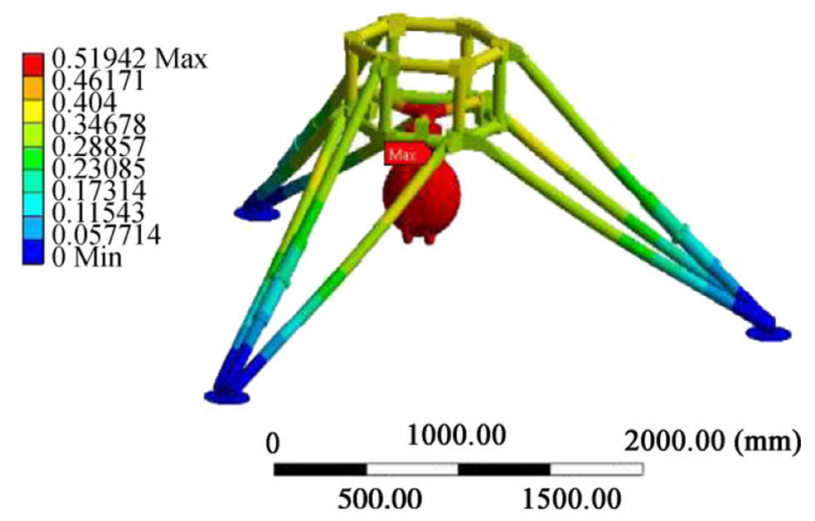

(a) Total deformation for load case No. 1
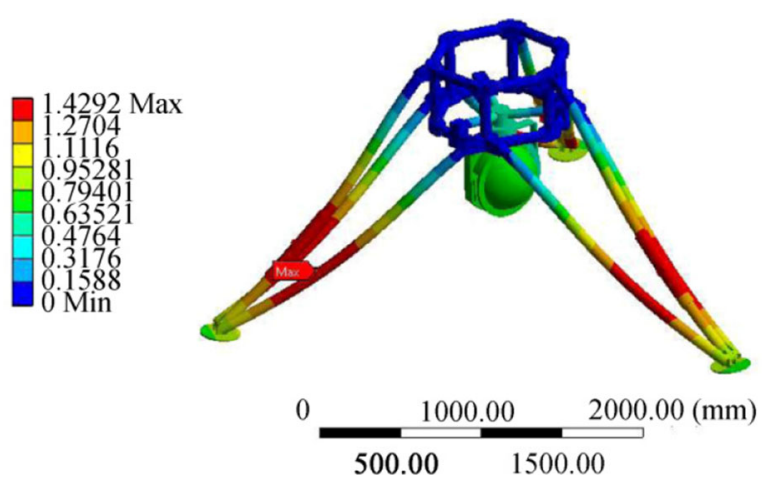

(b) Total deformation for load case No. 2

Figure 6 Total deformation for load case Nos. 1 and 2 using steel for the fork-shaped part

pressure was applied first, followed by the addition of weight to obtain faster and more concrete convergence. Regarding boundary conditions, the bottom of the structure was considered a fixed support, where rotation along the $x$-, $y$-, and $z$-axes is allowed but displacements are not. An appropriate mesh was generated using proximity and curvature to obtain smoother convergence with an average element quality of 0.79 ( 1 is best) and an orthogonal quality of 0.69 ( 1 is best). To verify the performed calculations, the weight of the structure was temporarily suppressed. With this, the reaction force on the boundary conditions must be equal to the buoyancy force, which, in turn, must satisfy Eq. (1). As expected, a reaction force in the opposite direction and equal in absolute value to the buoyancy force was obtained (Table 6).

For load case No. 1, the apparent weight (weight minus the buoyancy) is quantified as $511 \mathrm{~N}$, meaning that the lander weighs approximately $52 \mathrm{~kg}$ when submerged. Regarding deformations, the most significant effects occur on the forkshaped part, with a maximum value of $d=1.22 \mathrm{~mm}$. Similarly, major stresses were verified on this location, where $\sigma=0.98 \mathrm{MPa}$, making it below the value for plastic behavior $\left(\sigma_{\text {yield }}=43 \mathrm{MPa}\right)$. Nonetheless, a conservative perspective was taken into account and the fork-shaped part was manufactured using steel. 
Table 6 Results for load cases Nos. 1 and 2 using steel for the fork-shaped part

\begin{tabular}{lllll}
\hline Load case No. & Weight $(\mathrm{kg})$ & Force reaction $(\mathrm{N})$ & $\sigma(\mathrm{MPa})$ & Total deformation $(\mathrm{mm})$ \\
\hline 1 & 52 & 1624 & 5.47 & 0.519 \\
2 & 215 & - & 12.43 & 1.429 \\
\hline
\end{tabular}

In load case No. 2, the values for stress, strain, and displacements were obtained for a suspended structure from three eyebolts symmetrically dispersed on the upper hoop. Boundary conditions were considered to be of fixed supporttype on the three eyebolts, with Earth gravitational force working as stress. As a result of load case No. 1, the forkshaped part was considered to be out of steel. Again, as expected, an analysis of the displacements occurring on the lander clearly indicates that the greatest displacement was registered on the central part of the main supports because the central module has the greatest mass, creating a greater deformation on this area on impact. Given that the yield point again was not surpassed, we may attest that no risk of plastic behavior exists.

\section{Hyperspectral Camera, Sensorial System}

To develop a macroalgae detection system, the spectral data of macroalgae in a great number of development stages need to be obtained. The future application of the macroalgae detection system will be in situ, independent from external intervention. Given that the acquisition of spectral information of macro algae is performed in situ, the limitations that are raised by this type of measurement setup, the spectral properties of the algae, and the changes in these properties during their development are limited. Thus, the spectral imaging system should be able to acquire spectral information over a broad spectral range (Uhl et al. 2013). The algae and other objects in the target scene tend to move either due to ocean currents or because of the movement of the individual, such as in case of animals. Therefore, the measurement time should be kept as short as possible to prevent spectral and spatial blurring. A short image acquisition time is also desired to prevent significant changes in illumination depending on the measurement depth and intensity changes of the light due to clouds or other obscuring objects. As already addressed, several features can be used to address the performance of a spectral imaging system; spatial, spectral, radiometric, and temporal resolution. The parameters of these features are dictated by the combination of the spectral acquisition method, the sensor, and the lens of the imaging system. In addition, to develop the classification software, proper selection of the algae of interest is important. Images with a high spatial resolution and if possible a good RGB impression of the target scene will provide the user with high-quality information for proper annotation of the algae of interest. On the basis of these requirements, a multisensory non-scanning (or snapshot) hyperspectral camera was developed to provide the optimal combination of a large spectral range, reasonable spatial and spectral resolution, short measurement time, and co-registration of the color image with the spectral data.

\subsection{Snapshot Hyperspectral Camera Design}

A hyperspectral camera system consisting of a 41-band VIS/ NIR snapshot camera was developed at Quest Innovations. In this camera, three sensors were combined for optimal spectral imaging (Figure 7(a) and (b)). For 2D reference and to facilitate data annotation, a high-resolution (full HD) color image, recorded with an RGB sensor, was included with each hyperspectral dataset. The spectral bands were acquired using a $4 \times 4$ mosaic sensor for the spectral range of 470-630 nm; this sensor was referred to as the VIS sensor. The NIR sensor is a $5 \times 5$ mosaic sensor with a spectral range of $600-875 \mathrm{~nm}$ (Figure 8). The color image is co-registered with the hyperspectral data with subpixel accuracy, making accurate data fusion and visualization methods possible.

The mosaic filters in this hyperspectral camera are based on a tiled-filter approach where pixels are individually filtered with narrow Fabry-Pérot bandpass filters. This method allows real-time imaging at video frame rates without the need to scan in either spatial dimension.

\subsection{Additional Equipment}

The spectral imaging system consists of a combination of different components aside from the spectral camera. A micro PC was included to control the camera and allow data storage; a light source was included to acquire data using a controlled illumination source, as well as batteries for the power supply and integrated time switches to turn the equipment on and off during the trial. The Intel Next Unit of Computing micro PC was selected because its reduced size allows for simple integration in the lander. Windows 10 (Microsoft) OS was used to directly implement the software for the camera control and data acquisition. Complete acquisition of images was guaranteed with additional storage space. The battery requirements were defined based on the power consumption of the spectral imaging system, including all the additional components for 30 days of operation. To overcome a spatial constraint inside the glass sphere, one of the batteries was attached to the 
Figure 7 The camera and an impression of the sensor chip technology used

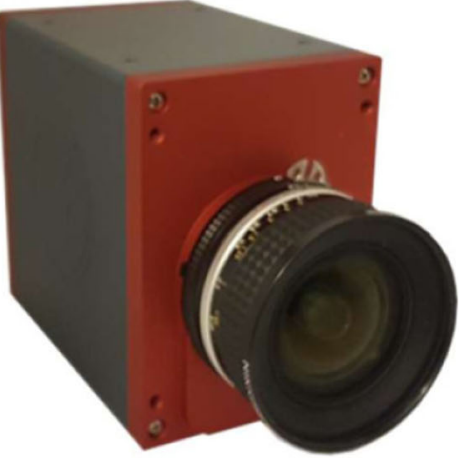

(a) Hyperspectral camera

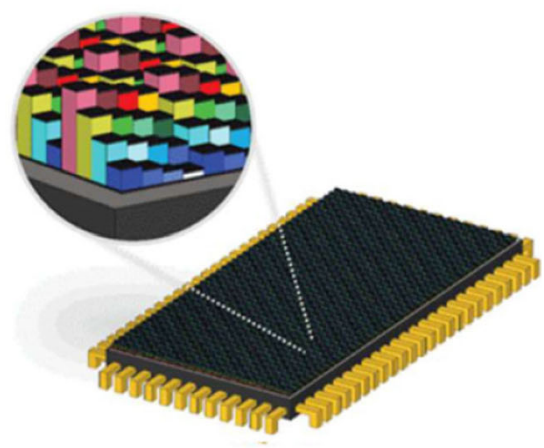

(b) Sensor chip technology used lander, this requiring water resistance. The selected battery set consists of two LifePo4 $24 \mathrm{~V} 15$ Ah Battery packs with a watertight enclosure.

\section{Laboratory Trials}

Two sets of laboratory trials were taken into account: (1) Preliminary trials, where the watertightness test of the glass sphere, tests of the batteries and of the monitoring system when subjected to vacuum $\left(p=0.2\right.$ bar, 1 bar $\left.=10^{6} \mathrm{~Pa}\right)$, and camera focusing tests were performed; (2) main trials, where lens focusing, structural stability, and full monitoring tests were performed. Preliminary tests took place at the Laboratory of Robotics and Autonomous Robotic Systems of the Faculty of Engineering of the University of Porto and main trials took place at the Laboratory of Autonomous Systems (LSA) of the Polytechnic Institute of Porto. The Laboratory of Robotics and Autonomous Robotic Systems has a water tank with a depth of $2 \mathrm{~m}$ and a breadth and width of $4.5 \mathrm{~m}$, which is appropriate for small-scale testing. LSA possesses a rectangular tank that is $10 \mathrm{~m}$ long, $6 \mathrm{~m}$ wide, and $5 \mathrm{~m}$ deep, making it ideal for larger laboratory trials.

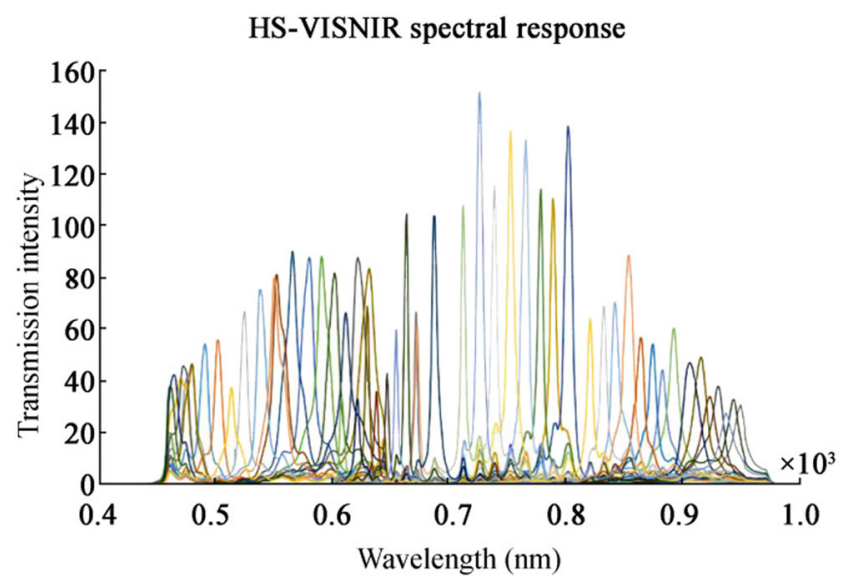

\subsection{Preliminary Trials}

As mentioned earlier, preliminary trials consisted of watertightness tests of the sphere, batteries, and camera performance tests when subjected to vacuum ( $p=0.2$ bar), and focal tests. The watertightness tests took place over a 4-day period. On day 1, the two semi-spheres of the Nautilus 17" sphere (Nautilus Marine Services 2019) were connected using TEROSTAT and Scotchrap 3 tapes for insulation in a clean temperature- and humidity-controlled room (Table 7). To measure the humidity variations, humidity stickers that had had three levels of humidity measurers (circular dot), namely, $20 \%, 40 \%$, and $60 \%$, were used. Whenever a certain humidity level was reached, the stickers' color changed from blue to pink. In this particular case, given that the humidity levels were at $44 \%$, two humidity variations were instantly verified and only one blue dot is visible (Figure 9(a)). After being sealed, the sphere was subjected to 0.2 bar (value suggested by the manufacturer). Electronic equipment was not used due to the risk of damage. Results showed that the no-alteration state could be verified (humidity remained $<60 \%$ over the four-day period), validating the use of this equipment.

In parallel, some tests were executed regarding the workability of the equipment when subjected to a pressure of 0.2 bar in a vacuum chamber. Results showed that the batteries fluctuated in size and electric capacity when subjected to 0.2 bar, thereby resulting in a pressure reduction ( $p=0.8$ bar) and culminating in a second trial. Overall, the results were similar, validating the use of this pressure. The focus test aimed to verify the effect of the curvature of the sphere on the obtained picture frame (Figure 9(b)). A triangular structure was positioned on the tank bottom to serve as object.

Table 7 Clean room temperature and humidity levels

\begin{tabular}{ll}
\hline Temperature $\left({ }^{\circ} \mathrm{C}\right)$ & Humidity $(\%)$ \\
\hline 23.3 & 44 \\
\hline
\end{tabular}

Figure 8 Hyperspectral camera bands from the VIS and NIR sensors 


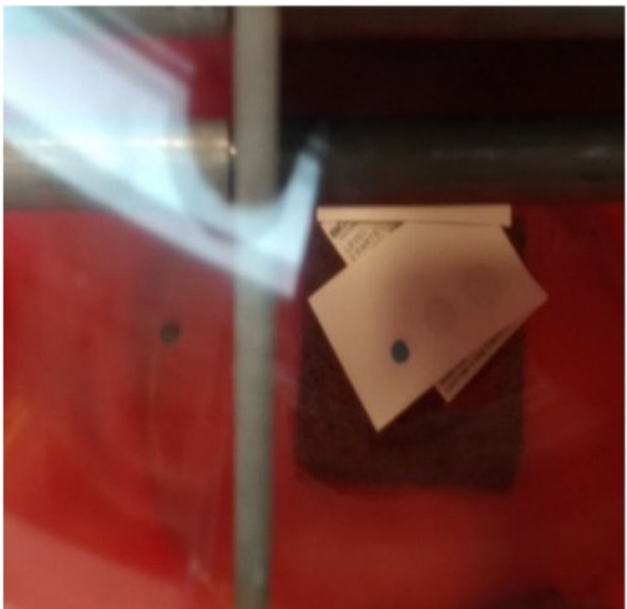

(a) Humidity control stickers located inside the sphere indicating humidity below $60 \%$ (blue dot)

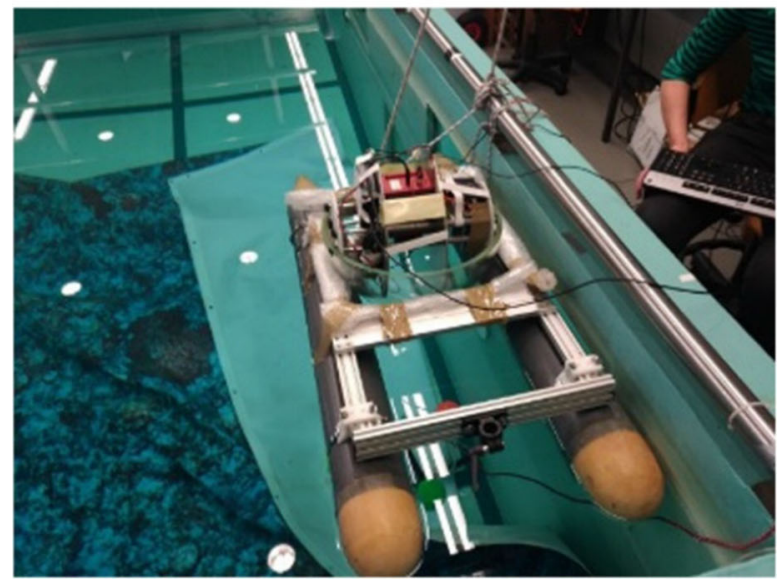

(b) Camera performing focus tests

Figure 9 Preliminary tests

Results validated the full functioning of the camera and the use of spectral imaging to gather information on submersed objects (Figure 10), because differences in reflection can be observed for the different colors of the spheres for the individual wavelengths (Figure 11).

\subsection{Main Trials}

In the preliminary stage, the lens was again focused by using the previously mentioned object placed on the tank bottom. In parallel, the humidity and vacuum pump from Nautilus (Nautilus Marine Services 2019) were used to remove all the humidity inside by using a drying desiccant cartridge, resulting in an almost humidity-free environment inside the glass sphere. The unequipped lander was then subjected to watertightness and structural stability tests under low vacuum ( $p \cong 1$ bar) (Figure 12(a)). After $24 \mathrm{~h}$, the need for a vacuum

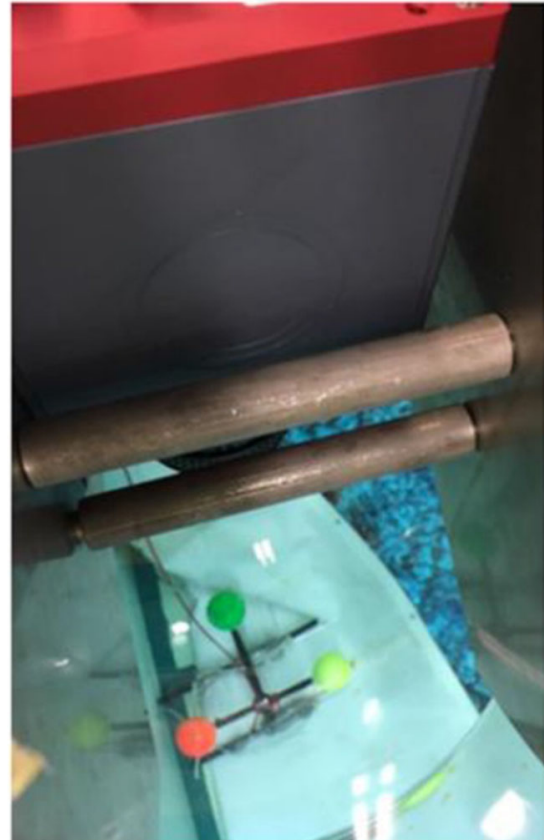

Figure 10 Impression of the imaging setup

inside the sphere was negligible even for low depths $(5 \mathrm{~m})$ because the hydrostatic pressure (1.5 bar) was enough to maintain the system watertight. Hence, the vacuum was no longer considered a requirement for sea trials, reducing the risk of damage to the electronic equipment. Moreover, a visual inspection of reference points on the legs and articulations of the structure verified that no deformations were present on the structure. As a result, the vacuum was removed from inside the sphere and full monitoring trials were performed (Figure 12(b)). Results of spectral imaging, watertightness, and structural integrity were similar to the ones mentioned beforehand, thus validating the proposed prototype.

\section{Installation Site}

The location chosen for the installation of the AMALIA lander was on the southernmost cove of the Berlenga Grande Island, also known as Cova do Sono. The Berlengas Islands are located just off the coast of Peniche, Portugal. Cova do Sono was chosen because it is a restricted area and because of the appearance of several invasive macroalgae common on the northwestern Iberian Coast, making it ideal for initial testing (Figure 13). The installation took place at a depth of $10 \mathrm{~m}$, which surrounds the entire island, and is very close to the $50-\mathrm{m}$ barrier, which connects the coast of Peniche and the Berlenga Grande Island. A water quality measurement sensor was installed for further monitoring. Periodic inspections and cleaning operations of the glass surface are currently being conducted, and future self-cleaning systems are being considered. 
Figure 11 Images obtained from the submersed object by the hyperspectral camera
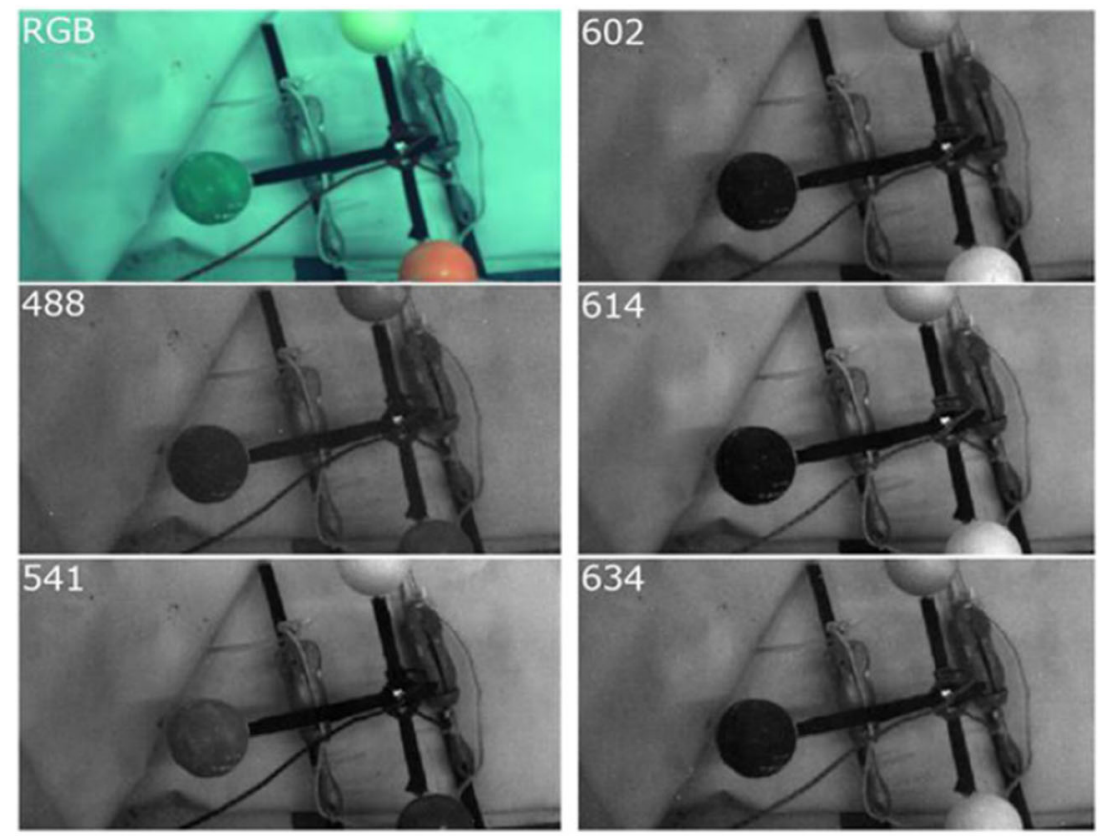

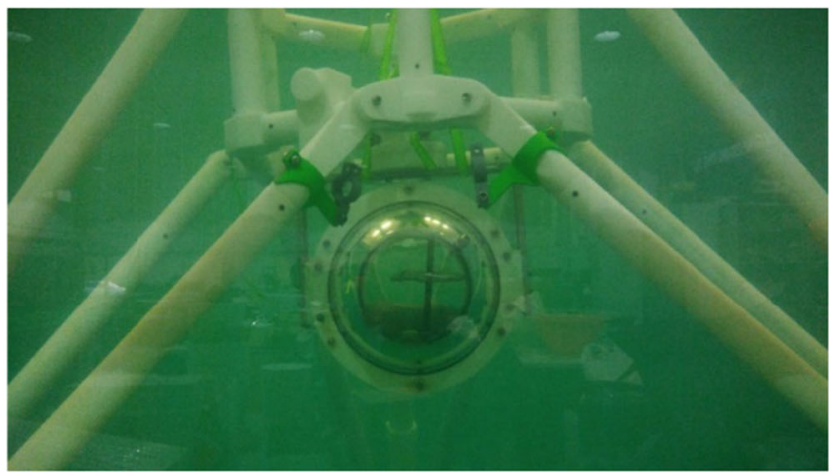

(a) Watertightness test with low vacuum

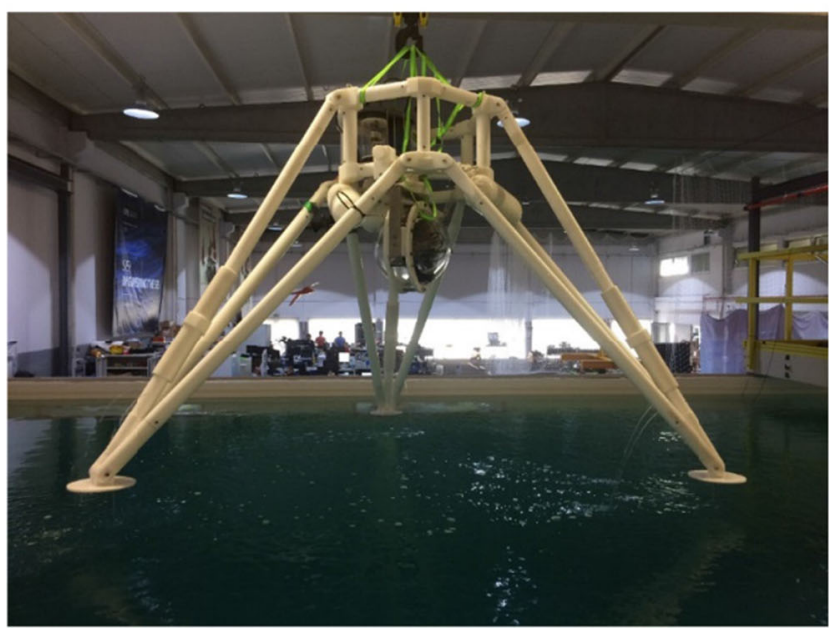

(b) Full lander test

Figure 12 Main trials

\section{Conclusions}

The AMALIA project aimed to idealize, conceptualize, and test a modular open-frame lander that can monitor macroalgae in the photic zone in situ. A preliminary assessment of existing landers and monitoring system was performed, creating a basis for the conceptual design. Six concepts were idealized and subjected to a screening process to determine the concept to be further developed. To determine the structure's dimensions, buckling criteria were considered and a numerical model for two load cases was created. A state-of-the-art camera was produced using RBG, VIS, and NIR sensors, allowing for the determination of invasive macroalgae through various bandwidths, and a fully operational monitoring system was obtained. Full-scale laboratory trials were performed, focusing on watertightness, structural stability, lens, and monitoring system accuracy. The

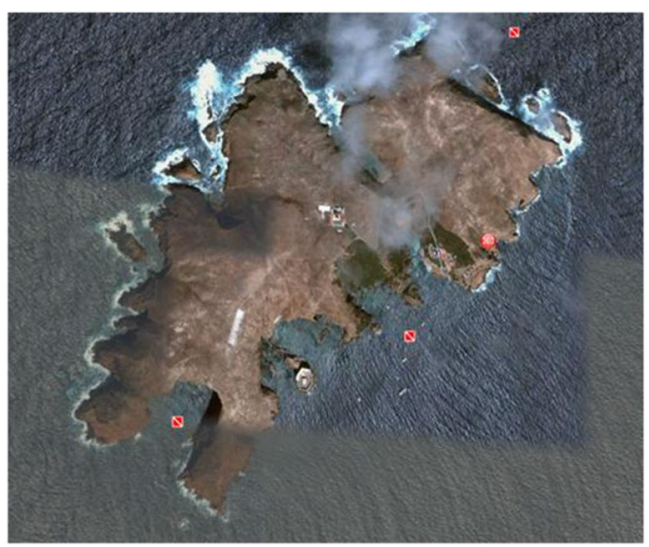

Figure 13 Berlenga Grande Island. Source: Google Earth 
following conclusions were derived from the numerical models and laboratory trials:

1) The application of spectral cameras for macroalgae monitoring and identification is suitable for different visibility conditions.

2) The structural stability and watertightness of the lander are easily achieved with the use of POM for the structure and a glass sphere for the camera, thus reducing the need for steel applications in lander construction.

3) The modular design of the lander allows for different systems to be attached to it, thus increasing the range of applications of open-frame landers.

Currently, sea trials are taking place at Cova do Sono, Berlengas Islands. This state-of-the-art prototype will allow information to be acquired on the amount of invasive seaweeds that are currently afflicting fauna and flora on the Portuguese Coast, and it can help determine which of these can be harvested and reused for industrial applications, such as the pharmacological industry. The developed lander allows for the introduction of other measuring equipment, such as AUVs for exploration of the surrounding areas, creating a hub and a new breakthrough in ocean exploration. Once data are collected, a macroalgae identification system can be developed for further studies.

Funding Information This study is supported by the European Union under Grant No. EASME/EMFF/2016/1.2.1.4/03/SI2.750419, and the AMALIA - Algae-to-Market Lab Ideas Project.

Open Access This article is licensed under a Creative Commons Attribution 4.0 International License, which permits use, sharing, adaptation, distribution and reproduction in any medium or format, as long as you give appropriate credit to the original author(s) and the source, provide a link to the Creative Commons licence, and indicate if changes were made. The images or other third party material in this article are included in the article's Creative Commons licence, unless indicated otherwise in a credit line to the material. If material is not included in the article's Creative Commons licence and your intended use is not permitted by statutory regulation or exceeds the permitted use, you will need to obtain permission directly from the copyright holder. To view a copy of this licence, visit http://creativecommons.org/licenses/by/4.0/.

\section{References}

Barbero E, Tomblin J (1993) Euler buckling of thin-walled composite columns. Thin-Walled Struct 17(4):237-258. https://doi.org/10. 1016/0263-8231(93)90005-U

Barbier EB (2017) Marine ecosystem services. Curr Biol 27(11):R507R510. https://doi.org/10.1016/J.CUB.2017.03.020

Domokos G, Holmes P, Royce B (2000) Constrained Euler buckling. Mechanics: from theory to computation. Springer, New York, pp 413-446. https://doi.org/10.1007/978-1-4612-1246115

Erhard G (2013) Designing with plastics. Carl Hanser Verlag GmbH Co KG
European Sea Observatory Network (2008) Deep-ocean environmental long-term observatory system. ESONEWS:2-5 Available from http://www.esonet-noe.org/content/download/20734/300257/.../

Ferreira H, Martins A, Valente A, Figueiredo A, da Cruz B, Camilo M, Lobo VS, Pinho C, Olivier A, Silva E, Almeida JM (2014). TURTLE - systems and technologies for deep ocean long term presence. OCEANS'14 MTS/IEEE, St. John's, Canada, 1-10. https://doi. org/10.1109/OCEANS.2014.7003138

Geyer RA (ed) (2011) Submersibles and their use in oceanography and ocean engineering. Elsevier

HADES (2014) HADAL-Lander A. Available from https://web.whoi. edu/hades/hadal-lander-a/ [Accessed on April 10, 2019]

K.U.M. Umwelt- und Meerestechnik Kiel GmbH (2002). Lander K/MT 100. Available from http://www.kum-kiel.de/fileadmin/pdf/en/ Datenblatt_Lander_eng.pdf

Kongsberg Group (2015) K-Lander autonomous seabed sensor carrier. Available at: https://www.kongsberg.com/globalassets/maritime/ $\mathrm{km}$-products/product-documents/k-lander-autonomous-seabedsensor-carrier

Kramer IR, Demer LJ (1961) Effects of environment on mechanical properties of metals. Prog Mater Sci 9(3):133-199. https://doi.org/ 10.1016/0079-6425(61)90020-2

Lu G, Lu G, Fei B (2019) Medical hyperspectral imaging: a review. J Biomed Opt 19(1):010901. https://doi.org/10.1117/1.JBO.19.1. 010901

Monnerie L (1990) Mechanical properties of polymeric materials. Stat Mod Fract Disord Media:66-76. https://doi.org/10.1016/B978-0444-88551-7.50012-4

Nautilus Marine Services (2019) Instrument Housings - vitrovex. Available from https://www.vitrovex.com/instrumenthousings/\# spheres [Accessed on May 6, 2019]

Pierre Beer F, Russell Johnston E (1981) Mechanics of materials. Ed. Ferdinand P. Beer, E. Russell Johnston. SERBIULA (sistema Librum 2.0)

Qin J, Chao K, Kim MS, Lu R, Burks TF (2013) Hyperspectral and multispectral imaging for evaluating food safety and quality. J Food Eng 118(2):157-171. https://doi.org/10.1016/j.jfoodeng. 2013.04.001

Shah VP (2007) Design considerations for engineering autonomous underwater vehicles. (Doctoral dissertation, Massachusetts Institute of Technology)

Silva E, Martins A, Almeida JM, Ferreira H, Valente A, Camilo M, Figueiredo A, Pinheiro C (2016) TURTLE - a robotic autonomous deep sea lander. OCEANS 2016 MTS/IEEE, Monterey, 1-5. https:// doi.org/10.1109/OCEANS.2016.7761262

Spagnoli F, Penna P, Giuliani G, Masini L, Martinotti V (2019) The AMERIGO Lander and the Automatic Benthic Chamber (CBA): two new instruments to measure benthic fluxes of dissolved chemical species. Sensors 19(11):2632. https://doi.org/10.3390/ s19112632

State of Green; Aarhus University (2018) Macroalgae as a new source of bio-based products. Available at: https://stateofgreen.com/en/ partners/aarhusuniversity/solutions/macroalgae-as-a-new-sourceof-bio-based-products/

Tengberg A, De Bovee F, Hall P, Berelson W, Chadwick D, Ciceri G et al (1995) Benthic chamber and profiling landers in oceanography - a review of design, technical solutions and functioning. Prog Oceanogr 35(3):253-294. https://doi.org/10.1016/0079-6611(95) 00009-6

The Ocean Portal Team (2016). The Deep Sea $\mid$ Smithsonian Ocean Portal

Uhl F, Oppelt N, Bartsch I (2013) Spectral mixture of intertidal marine macroalgae around the island of Helgoland (Germany, North Sea). Aquat Bot 111:112-124. https://doi.org/10.1016/j.aquabot.2013.06. 001

Universitat Politécnica de Catalunya (2019) OBSEA. Available from https://obsea.es/about/overview.php [Accessed on April 9, 2019] 
US Department of Commerce, National Oceanic and Atmospheric Administration (2018) What is ocean exploration and why is it important? Available at: https://www.oceanexplorer.noaa.gov/ backmatter/whatisexploration.html

Van der Wal D, Van Dalen J, Wielemaker-van den Dool A, Dijkstra JT, Ysebaert T (2014) Biophysical control of intertidal benthic macroalgae revealed by high-frequency multispectral camera images. J Sea Res 90:111-120. https://doi.org/10.1016/j.seares. 2014.03.009

Wynn RB, Huvenne VAI, Le Bas TP, Murton BJ, Connelly DP, Bett BJ, Ruhla HA, Morris KJ, Peakall J, Parsons DR, Sumner EJ, Darby SE, Dorrell RM, Hunt JE (2014) Autonomous underwater vehicles (AUVs): their past, present and future contributions to the advancement of marine geoscience. Mar Geol 352:451-468. https://doi.org/ 10.1016/j.margeo.2014.03.012 